\title{
RIPS: A Good Input to do Business Intelligence
}

\author{
Luis Enrique Gonzalez Duran* \\ DTeacher Cathedral Esp Management, Audit of Quality in Health University, Colombia
}

Submission: March 23, 2017; Published: May 03, 2017

*Corresponding author: Luis Enrique Gonzalez Duran, Teacher Cathedral Esp Management, Audit of Quality in Health University, Colombia, Email: enriquegonzalezduran@hotmail.com

\section{Abstract}

This document aims to highlight a database that exists in all hospitals, which in many cases is not used for anything and it just has been wasted over the last 10 years. Since it is a tell RIPS, their origins and therefore without entering basic details of the flat file, what tools can be used to get juice to the wealth of information and reports arising from them. This article wants to show the wider community benefits developed OLAP cubes for BI or Business Intelligence and how to think about the patient who comes to the public capital district.

The present article, to show in a quick and simple way, so that the RIPS is used or should be used in a hospital entity in Colombia. The first thing that could be said is that the Individual Registries for the Provision of Health Services (RIPS) had their origin in resolution No. 2542 of July 02,1998, issued by the Ministry of Health "By which data are determined Minimum, responsibilities and flows of information of health provision in the general system of social security in health. " Likewise, Resolution No. 2546 of July 17, 1998, issued by the Ministry of Health (RIA), "by which the guidelines in relation to individual care registration are dictated."

Subsequently, through resolution 3374 of the year 2000, the "Individual Registry of Health Services Provision" is defined, which is the set of minimum and basic data that the general health social security system requires for the processes of management, regulation and Control and support of the sale of service".

All this information collected in the databases of the Hospital can be used to structure business plans, could give the lights in the hospital to combine all this information into an analysis tool, which allows strategic decisions, analysis of atypical diseases (rare), Analysis of epidemiological profiles, integration of costs with billing and production, to mention some of the results obtained with all this information.

What should be the use of all this information? What is the relevant Information Management to manage all this information?? The must be of course, is focused on what hospitals should do with all this information, who can manage on these databases. It is clear that hospitals have possession of information, but, what decisions should managers make?

It is worth commenting in this article about the reliability of this entire database, who is the ones who upload it to the system and who manipulate it. Unfortunately, this system, which behaves very similarly throughout the hospital network in Bogotá dc. There are several sources that carry this information to this large database; among others are the Billers, the Physicians, among others, the entry assistants, the Pharmacy, among others. The information stored there and generated by the attentions to the patients, allows thinking that it becomes very reliable before being uploaded the validators of the entities that request these registers.

Given the large amount of this information, which is the best tool to make a true Information Management?. There is a tool that would allow for the empowerment of decisions, using Market Intelligence. The tools of the market intelligence allow to clearly showing the client that is coming to the hospital, positioning of hospital products, more relevant care, complex procedures and of course those that are in accordance with the level of the hospital. It should be noted that this analysis would be relevant in second and third level hospitals. The best known tools in what is called Business Intelligence, among others is PENTAHO, open source tools, that is, free on the net, is developed to support management decisions. Another tool that although not free, has a great reach in the handling of the cubes of information is ORACLE and its modules of support [1,2].

\section{Olap Cubes-The Solution}

TA third level hospital handles approximately 160,000 monthly records, where the bulk of the information is centered on the records of procedures, hospitalization and external consultation, all of which would help produce a more in-depth analysis of all internal and external movements of the same, To correlate in Cubes of Information a series of variables that very well structured would create. Recall that an Information Cube, also called OLAP Cube (Online Analytical Processing) or Online Analytical Processing, term coined by Mr. Edgar Frank Codd, is a multi-database. This database can be made up, in the file of Procedures, by the identification of the patient, the age, procedure performed, date of the procedure, alive or dead, 
paying (EPS insurer). But also, the OLAP cubes can interrelate information, taking the records of UA Emergencies, AP procedures, correlating them with those of AC Consultation, as well as those of $\mathrm{AH}$ hospitalization. This interconnection of files will allow establishing, for example, how many patients who are hospitalized entered by emergency, or entered by external consultation, to follow up procedures that were performed to these patients in both emergency and hospitalization. Likewise, with this information, it would be possible to cross the billing area and observe the closure of a care account, the cost of the care per patient, the number of patients treated, the medications provided if they are POS or Not POS, The cost of them, as well as being able to know the treatments, although not in detail, but to know how these patients were treated. As can be seen in this set of ideas that converge in this article, what is sought is in the medium term, when using this cube is to improve the costing strategies within the hospital care in Level III.

The following chart shows how the bases for making the corresponding consignments to the control body, the Secretary of Health, are set up, particularly since they are intended to validate this data through a special validator. This is the only use that RIPS have for the moment within a hospital, whatever its level (Figure 1).

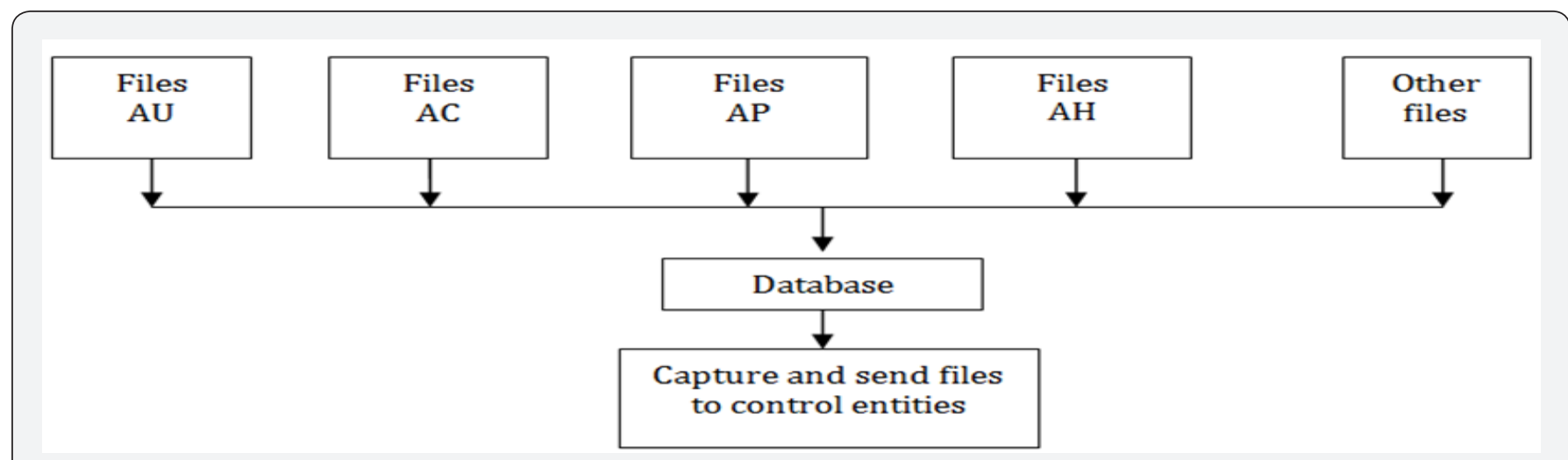

Figure 1: Information flow to assemble shipments to control entities.

Let's look now, how could the proposal for the application of business intelligence be structured using the RIPS of a Level III Hospital. It seeks to carry out a process that gives, among others, a speed in information, and additionally, seeks to validate these, since they present some inconsistencies, that is, improve their reliability. Situations where the patient's age does not agree with the diagnosis, patients treated with changed genres, patients presenting with duplicates in the medical records, are among some of the inconsistencies present in these files. The proposal also involves a process of data validation, in which there will surely be a corrector of those records that induce errors of appreciation and low reliability. It is important to remember that the entries have sources that have been classified into two groups, all of the care records here are those that have to do with external consultation, procedures, hospitalization, emergencies, among others and non-assistance in which the process is Billing, pharmacy, all these records come to a large database and from here are derived two large outputs, one that is relevant to the hospital, ie, there will be all external and internal reports, and the other great output is The one that has to do with that of the validator (Rips corrector), and this then passes to the BI Tool, passing to the creation of the OLAP cube so that this in turn allows to make the decisions that the hospital requires. Who should carry out this activity? Surely an information analyst (statistician) who works in key with the Sub-managers, with the Management and the Planning Office. This information will be considered strategic for the hospital (Figure 2).

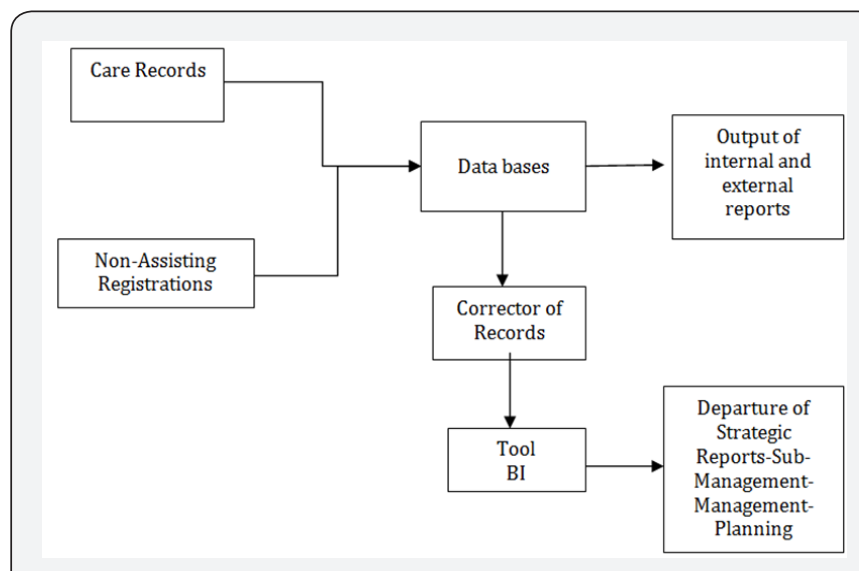

Figure 2: Proposed application of $\mathrm{BI}$ tool for a Hospital.

In essence, what this article seeks to show is that hospitals in Bogotá's public network, especially those at level II and III are an endless source of information, if each hospital were to operate any of the BI tools, The institutions will make decisions with greater knowledge of their patients, which in the end are the primary clients and the most important focus of care in the hospital network. Here, however, emphasis has been placed on applying BI tools for $2^{\text {nd }}$ and $3^{\text {rd }}$ level hospitals, but would it be worth applying to Tier I hospitals? The answer is simple, if you want to improve care to perform what the experts call $\mathrm{P}$ and $\mathrm{P}$ (Advocacy and Prevention), since level I hospital care focuses on these topics only. The proposal is tied to the topic of Hospital Care 
Networks in the Capital District. These networks seek to support the issue of demands for care by territories. Hospital information systems will soon be integrated into a large information center being led by the District SDS. It is clear that by the end of 2014, a pilot test should be in place to begin integrating referrals and against referrals from health services. Likewise, the information obtained from this great information accumulation center will surely accommodate BI tools, which should be designed in such a way that it has a robust cube to offer information that supports the Secretary of Health and, in passing, helps to the crossing of information with the corresponding hospital. I leave to the internal and external university community of our great institution this set of ideas, hoping that they will produce a positive impact and the discussion about what should be done with all the information accumulated in the health institutions of Colombia remains open.

\section{References}

1. Salgado A (2009) Individual registry of the provision of health services. Bogotá DC, Colombia.

2. Kroenke D (2009) Processing of Databases. Fundamentals, In: Editorial Pearson (Ed.), Design and Implementation $\left(8^{\text {th }}\right.$ edn), Washington, USA.

\section{Your next submission with Juniper Publishers} will reach you the below assets

- Quality Editorial service

- Swift Peer Review

- Reprints availability

- E-prints Service

- Manuscript Podcast for convenient understanding

- Global attainment for your research

- Manuscript accessibility in different formats ( Pdf, E-pub, Full Text, Audio)

- Unceasing customer service

Track the below URL for one-step submission https://juniperpublishers.com/online-submission.php 